\title{
O território como recurso: a privatização das telecomunicações no Brasil. Do leilão dos fragmentos à totalidade do território*
}

Fábio Tozi $^{* *}$

\section{Resumo}

Este artigo sugere uma reflexão geográfica para as privatizações ocorridas no Brasil. Partindo da alienação do sistema de telecomunicações, propomos pensar os processos ocorridos e suas relações com a totalidade do território (sistemas de objetos e ações) e não apenas as implicações para um setor econômico, como normalmente trata-se a privatização. Portanto, o que nos orienta é a idéia de território usado, sinônimo de espaço banal, o espaço de todos os agentes (SANTOS, 1994b), e não apenas o espaço das redes. Assim, além de uma análise empírica, esperamos colaborar para uma discussão sobre a pertinência da Geografia para o entendimento do Brasil e do mundo no presente.

Palavras-chave: Uso corporativo do território; Política pública; Geografia política; Privatizações; telecomunicações.

* Este artigo avança sobre algumas das discussões de nossa dissertação de mestrado realizada sob orientação do Prof. Dr. Márcio Cataia, na Pós-Graduação em Geografia do Departamento de Geografia da Unicamp

** $\quad$ Mestre em Geografia pela Unicamp, Professor do UNIFIG - Centro Universitário Metropolitano de São Paulo (fabio.tozi@gmail.com).

Geosul, Florianópolis, v. 24, n. 48, p 47-66, jul./dez. 2009 
TOZI, F. O território como recurso: a privatização das telecomunicações ...

The territory as a resource: the privatization of the telecommunications in Brazil. From the fragments auction to the totality of the territory

\begin{abstract}
This article suggests a geographical discussion about the privatization, starting from the alienation of the Brazilian's telecommunication enterprises which occurred in the last few decade. The article aims to start not by the economy view or one of its sectors, as usual, but by the analysis of the whole territory, know as a totality system (a system that involves, at the same time, objects and actions). This way, according to Santos (1994b), we intend to discuss the used territory which means the territory used by all the social agents, and not only the enterprise's and the network's territory. Besides the empirical analysis, we have achieved understanding the presently Brazilian territory where there is a fast and hard globalization and also a fragmentation process have caused essentially by the corporative action connected with the Brazilian government politics.
\end{abstract}

Key words: Corporative use of the territory; Brazilian public policy; Political Geography; Privatizations; telecommunications.

\title{
Uma aproximação teórico-metodológica: território e privatização
}

A globalização é antes de tudo uma metáfora. Espacialmente, ela se dá de maneira seletiva, razão pela qual Milton Santos (1994a) afirma que não existe um espaço globalizado, mas sim espaços da globalização. Uma dessas concreções da globalização no território brasileiro é a privatização do sistema de telecomunicações. Se a constituição de 1988 garante o monopólio estatal nas telecomunicações, rapidamente, no ano de 1995, é aprovada a emenda n. 8 que aboliu esse monopólio. Este ato possibilitou que se aprovasse, já em 1996, a "Lei Mínima", que permitiu a entrada de empresas privadas competindo com as estatais na telefonia celular, e, em 1997, a Lei Geral de 
TOZI, F. O território como recurso: a privatização das telecomunicações ...

Telecomunicações substituiu o Código Brasileiro de Telecomunicações (de 1962). Finalmente, em 1998, realiza-se o leilão da Telebrás.

Naquilo que a história hoje deixa, a globalização é a realização das possibilidades técnicas que acumula toda a humanidade, posta, no entanto, a serviço do capital e não do homem (SANTOS, 1997). As tecnologias da informação é que permitem o funcionamento sistêmico de técnicas antes isoladas, e por isso a globalização é o ápice do processo de internacionalização do mundo capitalista (idem, 2000). Assim, quando a possibilidade da conversibilidade dos diversos sistemas técnicos está presente, ela é capturada pelas grandes empresas multinacionais no momento em que elas de fato podem fazer de todo o planeta a sua escala de ação. Mas tal presença global das empresas é exigente de um aporte estatal nacional. Por isso é que a globalização não é apenas técnica, mas também as ações que autorizam os funcionamentos técnicos (ibidem).

O Estado, ao mesmo tempo em que fomenta a implantação das redes das Novas Tecnologias da Informação e Comunicação, impulsiona a criação de Novas Ortopedias Territoriais ${ }^{1}$, ambas necessárias à "competitividade internacional" do território. Como argumenta Cataia (2003), as primeiras são necessárias à ação mundial dos grupos hegemônicos e as segundas à ação nacional desses grupos. Portanto, elas "não se dissociam, [já que] a sua existência conjunta concretiza-se em alguns territórios nacionais que, por razões estratégicas desses grupos, podem fazer parte do circuito produtivo elou especulativo do capital" (ibidem, 2003, p. 06). Concomitantemente, o Estado cria uma nova regulação que orienta os funcionamentos e os usos possíveis dessas tecnologias e ortopedias, em geral direcionando-as às demandas do mercado. Por isso, as grandes empresas, erroneamente vistas e analisadas como

${ }^{1}$ A noção de Novas Ortopedias Territoriais, cunhada por Cataia (2003), trata das modernizações técnicas agregadas ao território que lhe dão maior integração e fluidez, superando as limitações da natureza e propiciando a circulação da produção. 
TOZI, F. O território como recurso: a privatização das telecomunicações ...

independentes da esfera estatal, não estão e não agem sós, já que suas políticas se confundem com as do Estado, conformando relações e hegemonias. Os países centrais do capitalismo, as corporações a eles aliadas, e as organizações internacionais a eles submetidas se apropriam de parte da soberania dos outros Estados nacionais, como mostra Santos, B. de S. (1997), criando as condições perfeitas para uma solidariedade entre o global e o local, através do nacional.

É nesse mundo unificado e complexo e nesse território brasileiro denso e perversamente constituído que o imperativo da privatização do sistema de telecomunicações desponta. Se momentos históricos pretéritos possibilitaram avanços na privatização de alguns domínios da vida, a privatização vivida no Brasil ao final dos anos 1990 é cria e criadora de parcela do mundo atual, e se insere organicamente, mais e mais, nas relações, nos objetos, nos ideários, em todo o território, enfim. A privatização das telecomunicações possibilita, para a racionalidade do mercado, os suportes técnicos necessários ao período informacional da história. As tecnologias das telecomunicações privatizadas compõem a caracterização nacional do período: "longe de constituir fato isolado, a privatização das telecomunicações brasileiras se insere numa estratégia maior de Governo, em que capitais privados, independentemente de origem, passam a substituir o Estado na produção de bens e serviços" (PINHEIRO DA FONSECA, 1998, p. 14).

Este rápido processo da privatização representou a permissão para a criação, no território brasileiro, de uma nova camada técnica, com destaque para a telefonia celular e outras redes de transmissão de informações, que, pautando-se em critérios corporativos, espalharam desigualdades a partir da modernização desigual dos lugares.

Superando os determinismos criados por certa economia, a incorporação da dimensão territorial às análises sobre a privatização das empresas de telecomunicações no Brasil possibilita aprofundar e revelar novos fatos sobre as situações hoje 
TOZI, F. O território como recurso: a privatização das telecomunicações ...

existentes no país. Como o território caracteriza-se por materialidades e imaterialidades delineadas por normas, a análise da privatização não permite que a tratemos simplesmente como um setor da economia: há que se partir da dimensão territorial do processo, uma vez que ela possibilita o sucesso ou o esfacelamento de certas investidas, permitindo ou inibindo usos. É a idéia de espaço banal (SANTOS, 1994b, p. 16) a referência, ou seja, a de que o território usado é o de todos os agentes, com suas diferentes possibilidades e limitações. Assim, trata-se não apenas da privatização de um sistema técnico ou de serviços, mas a própria privatização do território brasileiro, que significa solidarizar a sua organização, regulação e uso para promover o benefício da reprodução do capital. É também o território, como propõe Souza (1999), fundamental à verdadeira política, pois que ele permite a crítica ao que existe mirando a uma democracia de fato, a partir dos lugares.

A privatização é, finalmente, para o método geográfico, um evento, entendido de acordo com Santos (1996, p. 115), como o veículo de algumas das possibilidades do mundo, filtradas pela formação socioespacial ${ }^{2}$ e selecionadas nos lugares, que são seus depositários finais. Trata-se de um evento, pois, a partir dele, criam-se novas situações, ou seja, novas coerências entre os sistemas de objetos e de ações, abarcando a totalidade do território e impondo, sem exceções, um novo rumo às relações espaciais. Dialogando com RIBEIRO (2001) podemos pensar o evento como o vetor que impulsiona uma sistematização em determinado arranjo do território, que, assim, tem que se reorganizar, configurando uma nova sistematicidade, qual seja, um novo funcionamento sistêmico dos elementos (objetos e ações). Esta relação permite, teoricamente, a aproximação à idéia de processo.

A rapidez da imposição de tal evento ao território, avesso a discussões e divergências, e a brutalidade das ações empreendidas

2 O conceito de formação socioespacial, elaborado por Santos (1996), reconhece que a Formação Econômica e Social apresenta inevitavelmente uma dimensão espacial quando historiciza o modo de produção. 
TOZI, F. O território como recurso: a privatização das telecomunicações ...

criou eficientemente as condições para a aceitação dessa nova situação no Brasil, hoje traduzida na inquestionabilidade das relações existentes. Esta transposição, que trata os acontecimentos como naturais ou eternos, é perigosa ao inibir um debate profundo e necessário sobre a democratização do território brasileiro.

\section{A globalização e a fragmentação do território brasileiro pelas privatizações}

A formação socioespacial brasileira acompanha, à sua maneira, o movimento do mundo, convivendo com o que lhe é solicitado, numa tendência a que influam, cada vez mais, elementos externos e não mais somente os internos. Há, portanto, uma forma de capitalismo especifica do território brasileiro.

Octávio Ianni (2004) fala da existência, inicialmente, de um projeto de capitalismo nacional que objetivava interiorizar os centros decisórios acerca dos problemas da economia política e redefinir amplamente os laços com os países mais fortes do imperialismo (EUA e Inglaterra). Tal projeto acabou por criar uma referência ao povo e às regiões brasileiras, ou seja, uma visão de dentro daquilo que eram as relações com o mundo. Este projeto de um "capitalismo nacional” é substituído por outro de "capitalismo internacional", no qual há uma primazia do mercado em detrimento do planejamento, impondo a ideologia de que o melhor caminho para o desenvolvimento é a associação do capital nacional com o internacional, independente de sua origem.

Marilena Chauí (2000, pp. 94-95) também ressalta as ações de uma política neoliberal no Brasil, que recrudesce presentemente a estrutura histórica da sociedade, isto é, a polarização extrema entre carência e privilégio. Torna-se possível o aumento do ganho de capital sem a incorporação de pessoas ao mercado de trabalho e consumo (desemprego estrutural), a privatização do público (transformação de direitos sociais em serviços privados adquiridos no mercado), o abandono das políticas sociais pelo Estado e a preferência pelos capitais privados nos investimentos estatais. 
TOZI, F. O território como recurso: a privatização das telecomunicações ...

Já Milton Santos propõe que o neoliberalismo é o braço político da globalização, e, ao mesmo tempo em que o seu discurso prega a ausência do Estado, atribui a ele a responsabilidade pela saúde econômica do país, necessária ao sucesso dos investimentos privados. Assim, o território brasileiro se transforma, cada vez mais, num espaço nacional da economia internacional (SANTOS, 1996, p. 194). O uso corporativo do território intensifica-se, e as infra-estruturas do país são mais bem utilizadas pelos projetos das grandes empresas do que pela população (idem, 1987; 1994b; 1996). E, uma vez que uma economia e um capitalismo globalizados continuam dependendo das políticas dos Estados nacionais, verificamos a existência, nestes, de ações que os alinham ao movimento do motor único do capital, das quais se destaca a privatização das empresas, resultado de um projeto para o Brasil que se casa a um projeto internacional de capitalismo e que é, de fato, mais ganancioso, ou seja, não se restringe a setores ou empresas, mas mira a totalidade do território, dos seus recursos.

Assim, o Estado, com a privatização, incentivou que empresas nacionais e multinacionais tivessem no território brasileiro um porto seguro. Como cada vez menos o Estado diferencia a empresa nacional daquela internacional, a própria globalização do território já está interiorizada, diluída nas relações comuns dos lugares, tão impregnada à economia, à cultura, à política, ao cotidiano a tal ponto que seu projeto internacionalizante se torna imperceptível nas práticas diárias da população, ou, graças ao suporte da psicoesfera ${ }^{3}$, é mostrado como avanço quando nem sempre o é.

Preparando o território para seus posteriores usos corporativos, houve um grande movimento do Estado investindo na criação e modernização de enormes infra-estruturas que foram transferidas para o comando privado. Esse processo, que tratamos

${ }^{3}$ A pscicoesfera é a dimensão imaterial do espaço, complementar a uma tecnoesfera. Para Santos (1993) ela é o reino dos desejos, vontades, ideologias, crenças e hábitos, que inspiram comportamentos e visões de mundo. 
TOZI, F. O território como recurso: a privatização das telecomunicações ...

como uma neo-acumulação primitiva (TOZI, 2005) graças à expropriação do patrimônio público e o revolucionamento das condições produtivas e dos modos de vida foi, ao mesmo tempo, vetor de modificação técnico-normativa do território brasileiro, já que a propalada "desregulamentação" do Estado significou a criação de mais normas para que a ação das grandes empresas pudesse realizar-se em novos patamares, fato que persiste. Sendo agora as responsáveis pelo funcionamento dos macro-sistemas privatizados, as empresas também governam.

Preparando o território para a privatização das telecomunicações, adotou-se uma reserva estatal de áreas específicas para cada empresa. Como as decisões e as regras finais sobre a privatização couberam ao Estado (apoiado em consultorias privadas), pode-se dizer que ele escolheu, facilitando ou dificultando a concorrência de tal ou qual grupo, quais empresas teriam prioridades de ação no território. O MAPA 01 mostra a divisão do território para o leilão das telecomunicações.

Para cada uma das quatro regiões foram escolhidas, via leilão, uma empresa concessionária e uma empresa espelho, que possuíam o monopólio legal sobre seus fragmentos do território. A existência de uma empresa espelho em cada área justificava a ideologia da concorrência proferida naquele momento.

Com a criação de consórcios para os leilões da Telebrás, e posteriormente com as fusões, as empresas passam a ter ingerências umas nas outras. Dividem, cooperando e competindo, projetos que envolvem a expansão de suas hegemonias pelo território: "as operadoras ocupam monopolisticamente fragmentos do mercado e compartilham umas com as outras o acesso a cada fragmento, assim ganhando todas" (DANTAS, 2002, p. 53). Nas palavras de Maria Laura Silveira (2003, p. 85) esses "são os monopólios territoriais, testemunhas do simulacro do livre mercado, pois a concorrência entre firmas globais se dá apenas no leilão das parcelas do território. Depois o Estado age como garantia da permanência do monopólio ou do oligopólio em uma dada região". A divisão do território nesse momento responde às 
TOZI, F. O território como recurso: a privatização das telecomunicações ...

necessidades do modo de produção vigente e faz lembrar de pelo menos um outro período de nossa história, com a divisão do Brasil em capitanias que criavam um mapa dos donos de cada uma das porções do território, respondendo também aos interesses hegemônicos do modo de produção naquele momento.

Mapa 01: BRASIL - A fragmentação do território brasileiro. Áreas de outorga da telefonia fixa (1998)

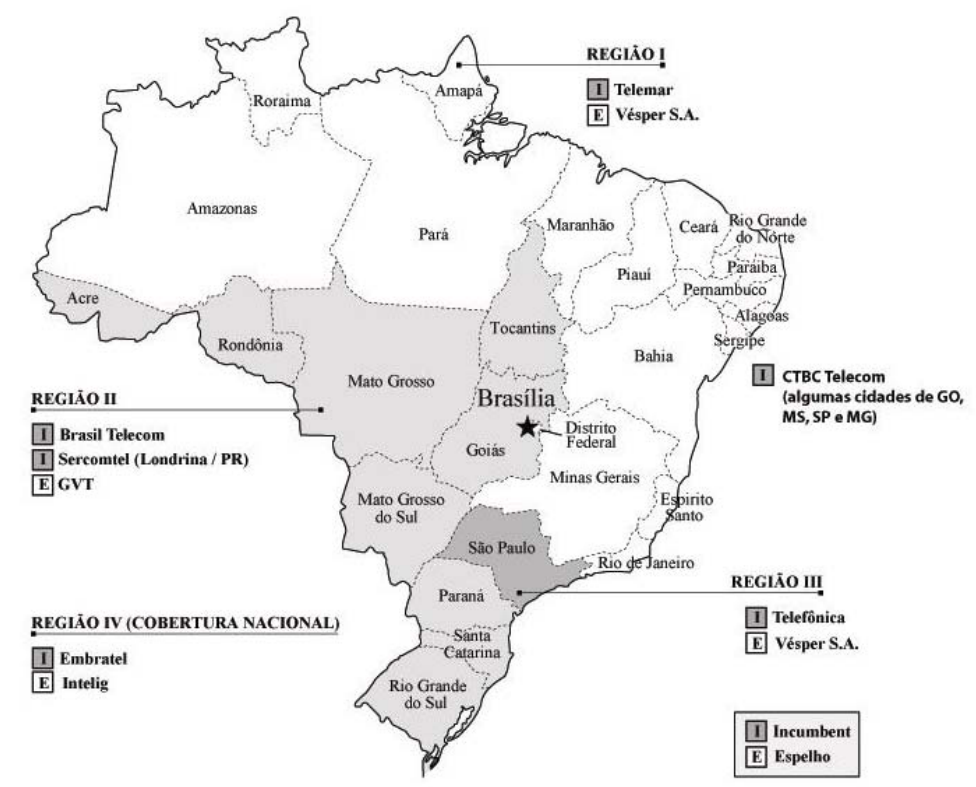

Elaboração cartográfica: Daniel Simas e Fábio Tozi.

Com base em: ANATEL / Atlas das Telecomunicações, 2003. Mapa sem escala.

A prometida concorrência, entretanto, nunca se realizou de fato, pois em 2003 (cinco anos após as privatizações), a empresa espelho que mais cresceu conseguiu apenas $4 \%$ do mercado na sua região (TOZI, 2005). Há, neste caso, uma questão territorial que se impõe ao engodo econômico da concorrência: como não existem redes concorrentes entre as empresas, não pode haver uma 
TOZI, F. O território como recurso: a privatização das telecomunicações ...

concorrência de fato. Para funcionar, uma empresa utiliza a rede das demais, prática conhecida como interconexão. Demais, a fragmentação do território para as privatizações apenas preparou-o para uma futura unificação privada, com a formação de grandes grupos a partir da fusão de empresas, situação presente também na telefonia móvel, como no caso das empresas Claro e Vivo ${ }^{4} \mathrm{Na}$ telefonia fixa, a legislação, ao menos até o momento, impede a fusão entre as operadoras regionais, todavia estas já pressionam o governo federal para que tal norma seja modificada.

A regionalização do território criada para o leilão (MAPA 01) permitiu que as empresas, nacionais ou não, escolhessem, no território, a região mais adequada aos seus projetos, dada a desigualdade territorial brasileira, que cria escassas e abundantes combinações entre objetos e informações. As empresas internacionais têm presença expressiva (superior a 50\%) em onze das treze regiões leiloadas no dia 29 de julho de 1998. A única empresa com capital 100\% nacional é a Tele Norte Leste (posteriormente Telemar) que, no entanto é uma empresa quase estatal, se tal classificação pudesse existir, pois o BNDES (Banco Nacional de Desenvolvimento Econômico e Social) detém 25\% das suas ações, os fundos de previdência do Banco do Brasil e Petrobrás outros $20 \%$ e duas subsidiárias do Banco do Brasil, 10\%. Tal composição é também resultado daquilo que foi tornado público através da divulgação de conversas telefônicas gravadas ("escândalo do grampo"), em que o Presidente Fernando Henrique Cardoso, o Presidente do BNDES, André Lara Resende e o Ministro das Comunicações, Luiz Carlos Mendonça de Barros

${ }^{4}$ A Vivo, criada em 2003, uniu as sete maiores empresas de telefonia celular do Brasil sob comando da Telefónica Móviles e Portugal Telecom. A Claro, comandada pela American Móvil (do grupo mexicano Telmex), também foi criada em 2003 pela fusão de cinco operadoras regionais.

5 Com a proposta de compra da Brasil Telecom pela Oi/Telemar, a ANATEL iniciou, em junho de 2008, a revisão do Plano de Outorgas para permitir que uma empresa compre outra fora de sua área de concessão. 
TOZI, F. O território como recurso: a privatização das telecomunicações ...

revelavam acordos com empresários cuja intenção inicial era que o consórcio comprador da Telemar tivesse arrematado, no leilão, a Telesp. Há aspectos das privatizações nunca esclarecidos, que envolvem ainda, além dessa negociata mencionada, os preços de venda, definidos por consultorias internacionais, e os ágios praticados no negócio, mostrando que ou as empresas foram mal avaliadas ou os investidores supervalorizaram seus preços, como também analisa Biondi (2001). Em qualquer dos casos, há uma deliberação das consultorias (que se pautam no "mercado") assumida pelo governo.

No leilão das empresas concorrentes - empresas espelho - a globalização do sistema de telecomunicações intensifica-se, e predomina o capital estrangeiro. Das quatro regiões leiloadas, em apenas duas houve participação de empresas brasileiras (regiões I e III), mesmo assim, esta participação é de apenas $2,5 \%$ do capital investido. Essa globalização do comando dos sistemas técnicos nacionais se repete, também, em outras privatizações, como a do sistema energético e do sistema bancário. A média da participação de investidores brasileiros no total das privatizações (sendo que $37 \%$ do total arrecadado com todas as privatizações originou-se dos leilões das telecomunicações), entre 1991 e 1998 foi de 61,2\%. No entanto, a partir de 1995, os investimentos estrangeiros aumentaram: em 1998, representaram 59\% do total, sendo que destes, 33,3\% eram estadunidenses, 27,9\% espanhóis e 16,9\% portugueses (dados fornecidos por Pinheiro \& Giambiagi, 2000; Cano, 2000).

Cabe ainda ressaltar que inicialmente não era permitida a participação de $100 \%$ de capital estrangeiro no leilão das empresas da telefonia fixa, regra que foi alterada, viabilizando a internacionalização das redes, da mesma forma como também se abrandaram, nas negociações anteriores aos leilões, as obrigações contratuais das empresas concessionárias, conforme mostram Dalmazo (2000) e Pinheiro da Fonseca (1998), o que não impediu que tais obrigações reduzidas fossem descumpridas, o que é atestado pela sucessiva liderança dos serviços de telefonia nos 
TOZI, F. O território como recurso: a privatização das telecomunicações ...

órgãos e procuradorias de defesa do consumidor, conforme analisamos em nossa pesquisa de mestrado (TOZI, 2005).

\section{Situações do território - alguns elementos para a crítica do presente e para pensar o futuro}

A prisão à sistematicidade, na qual o futuro possível parece ser somente aquele que reproduza as ações hoje hegemônicas, naturaliza as crises como necessárias à melhoria da vida e coroa $\mathrm{o}$ impossibilismo do Estado (BORON, 2004). Mas se aparentemente não é permitido pensar diferente, há que se considerar que no território as situações não são tão puras e sobressaltam outras necessidades. A privatização foi apresentada como a única opção possível ao país, negando, dessa maneira, o debate nacional, mas o território mostra que esse projeto não atende às demandas do espaço banal.

Em 1996, a "Lei Mínima" autorizou a entrada de empresas particulares na telefonia móvel, e em 1998 a rede celular, recém privatizada, atendia 1.231 localidades em todo o território nacional, estendendo-se pelo litoral do norte ao sul do país, interiorizando-se nos Estados da Região Concentrada ${ }^{6}$ e criando pontos luminosos no restante do território. Antes de suprir necessidades comunicacionais onde outras redes eram escassas, a telefonia celular soma-se aos lugares já densos de outras redes de informação ou naqueles em que a dinâmica avançada da produção exige uma comunicação rápida e flexível, como no Centro-Oeste, onde as localidades ligadas à telefonia móvel são aquelas nas quais se desenvolve uma agricultura moderna, informacional, conforme observaram Santos \& Silveira (2001). A rede de celulares integrou e integra desigualmente os lugares do território, seguindo lógicas empresariais, como veremos adiante.

${ }^{6}$ A Região Concentrada é a porção do território brasileiro em que o meio técnico científico-informacional está mais presente. É formada pelos estados de Rio de Janeiro, Espírito Santo, Minas Gerais, São Paulo, Paraná, Santa Catarina e Rio Grande do Sul. A denominação, de 1979, é de autoria de Milton Santos e Ana Clara Torres Ribeiro. 
TOZI, F. O território como recurso: a privatização das telecomunicações ...

O telefone celular é um objeto que atende às necessidades informacionais e comunicacionais dos espaços luminosos: móvel e rápido, permite seu uso em qualquer lugar e a qualquer momento graças à rápida criação das bases técnicas necessárias nesses subespaços escolhidos - além dos telefones celulares mundiais via satélite e acordos de transferência entre operadoras em todo o mundo - realizando just-in-time e just-in-place (SANTOS, 1996) a informação e a comunicação, especialmente com a adição de tecnologias e serviços de internet aos aparelhos. Nos novos lugares modernizados, a rede celular pode chegar antes que as redes tradicionais de informação. Essas características são chantagens ao seu uso, e por essa sua modernidade e utilidade, suas tarifas também são as mais altas.

Se as integrações anteriores do território tiveram o Estado como protagonista, a atual, no que tange às telecomunicações, tem as empresas: é uma integração corporativa do território. À flexibilidade possível das novas tecnologias não corresponde uma democracia do território. No entanto, como as ações dessas empresas recaem sobre todos os lugares, elas acabam por impor, à totalidade do território, suas próprias divisões territoriais do trabalho. Assim, o território é alienado, pois ao mesmo tempo em que o espaço se globaliza, ele se fragmenta. Um espaço humanamente desvalorizado, reduzido a uma função (FRÉMONT, 1976 citado por Santos, 1987), e um território recurso das empresas. Um novo impulso de internacionalização para um país que sempre teve redes voltadas para o exterior, já que, como destaca Dantas (2002, p. 129), “as infra-estruturas de transporte da informação dos países periféricos serviram, basicamente, à inserção internacional de suas economias, fonte de matérias-primas e mão-de-obra baratas para os países centrais. Secundariamente, forneceram redes telegráficas ou telefônicas para as classes ricas e remediadas".

Observem-se as metas de "universalização", ou seja, o projeto de extensão das redes pelo território, verdadeiro desenho de uma integração opressiva, pois uma vez que a universalização é o alargamento das redes das empresas, estas impregnam ainda mais as 
TOZI, F. O território como recurso: a privatização das telecomunicações ...

relações territoriais. A universalização, em sua leitura neoliberal, tem mais a ver com o consumo e a necessidade de lucro das corporações do que com as necessidades dos lugares em se comunicar. Universalização e integração do território não significam democratização do território. Portanto, embora a ANATEL (Agência Nacional de Telecomunicações) tenha atestado que as empresas de telefonia fixa cumpriram suas metas de universalização - declaração fundamental para que elas pudessem operar além de sua região inicial - o território nos revela uma situação inversa, como nos mostra Iozzi: "analisando a densidade telefônica correspondente ao ano de 2005 percebemos que essa relação é muito desigual no Brasil. Para mais de 4.500 municípios existem menos de 20 telefones para cada 100 habitantes, ou seja, esse índice é inferior a 20\%, que era a média nacional no ano de 2000. Aproximadamente 2.700 municípios apresentam densidade menor que $12 \%$ (média correspondente a época em que o Sistema Telebrás foi privatizado). Somente 44 municípios apresentam mais de 50 telefones por 100 habitantes" (IOZZI, 2005, p. 124).

Da mesma maneira, Azevedo (2005, p. 117), mostra que o serviço de telefonia fixa no município de Campinas, de acordo com os parâmetros da ANATEL, poderia ser considerado universalizado. Mera abstração das médias, pois numa análise territorialmente mais rigorosa, a partir de áreas de ponderação (agrupamento de dados dos setores censitários do IBGE), a autora mostra que há telefones onde há renda, fato que não é novidade para o município.

Os dados fornecidos pela ANATEL iludem ainda quanto ao número de linhas, pois considera as instaladas mesmo que não usadas. A ociosidade tem caracterizado o sistema de telecomunicações desestatizado. Perversidade da crise no território de uma lógica privada: enquanto grande parte dos lugares e das pessoas do Brasil não tem linha telefônica, sobram linhas ociosas nas empresas de telefonia. Em janeiro de 2002 havia 48 milhões de linhas no país, mas somente 36,5 milhões estavam em funcionamento. Cabe perguntar: qual a função social de redes sem uso? O que importa para a Agência é a capacidade das centrais (terminais instalados) e não os terminais de 
TOZI, F. O território como recurso: a privatização das telecomunicações ...

fato utilizados. Assim, em média, cerca de $25 \%$ das linhas das operadoras são ociosas. Em julho de 2004 a Telefônica possuía cerca de $15 \%$ de linhas não utilizadas. Já a Telemar, no ano de 2001, instalou três milhões de linhas e cortou 2,289 milhões por falta de pagamento.

$\mathrm{Na}$ telefonia celular houve um avanço da legislação em relação à telefonia fixa, dando maior liberdade às políticas empresariais, pois não há metas a cumprir perante ANATEL, tampouco se fez necessário, portanto, criar o discurso da universalização. É o coroamento do mercado sobre o planejamento, impossibilitando uma política brasileira de telecomunicações.

Embora fossem mais de 65 milhões de aparelhos celulares em 2004 (em 2008 já são mais de 100 milhões), eles estavam presentes em apenas 50\% dos municípios brasileiros, conforme Iozzi (2005, p. 149), para quem, "no final de 2004, 2.776 municípios do Brasil contavam com pelo menos uma operação de telefonia celular, em cidades que representavam 95,7\% do Índice Potencial de Consumo $(I P C)^{7}$. Em 2003 eram 2.546 municipios atendidos por esse serviço, englobando cidades que totalizavam um IPC de 94,6\%. Ou seja, 230 municípios elevaram o IPC em apenas 1\%". A distribuição das redes pelo território fica aprisionada à decisão das empresas, situação que, de acordo com Possebon (2005b apud IOZZI, 2005, p. 149) tende a ficar mais dramática, "já que os 4,7\% de mercados restantes estão distribuídos por nada menos que 2.788 municípios. Ou seja, se de um dia para o outro as teles celulares dobrassem a sua cobertura, ganhariam menos de 5\% de mercado potencial".

Assim organizados pela racionalidade do mercado, território e economia tornam-se empecilhos à democracia, já que além de muitos dos lugares não possuírem as redes de telecomunicações, a renda é também um impedimento ao seu uso. De acordo com a "Segunda Pesquisa sobre Uso da Tecnologia da Informação e da

\footnotetext{
${ }^{7}$ Para Iozzi (2005, p. 149), o IPC (calculado pela empresa Target) é um indicador fundamental para as decisões empresariais, pois mostra a participação de cada município na movimentação econômica do país.
} 
TOZI, F. O território como recurso: a privatização das telecomunicações ...

Comunicação no Brasil" (TIC), realizada em 2006 ${ }^{8}, 49,7 \%$ dos entrevistados possuíam telefone fixo, enquanto $68 \%$ possuíam telefone celular. Entretanto, entre estes últimos, 60,5\% utilizavam o telefone apenas para enviar e receber mensagens de texto, ou seja, faziam uso incompleto das possibilidades de comunicação. Neste caso, o telefone, que há mais de um século surpreendeu o mundo por transmitir a voz é usado, na atualidade, para outras funções, pois falar por meio dele ficou caro demais. Ainda de acordo com a pesquisa, em média, as pessoas que ganhavam até 3 Salários Mínimos gastavam R\$ 1,00/mês com o celular, preço aproximado de 1 minuto de ligação.

O território convive desigualmente com o meio técnicocientífico informacional: há um descompasso entre uma psicoesfera, ampla, que ilude quanto à modernização do país e uma tecnoesfera, restrita e seletiva, que impede e limita o uso dos objetos nos lugares. Tais situações territoriais provam o engodo do discurso das privatizações. Hoje, antes de enfrentar tais situações, as políticas de regulação do governo e suas Agências apenas adequam certos aspectos do funcionamento da sistematicidade vigente, não debatendo os fundamentos políticos dos eventos ocorridos, tampouco atentando-se à cidadania, mas apenas ao consumo. Tais ações regulatórias, lançadas como solução a certa crise latejante, não alteram a estrutura que gera tal crise ${ }^{9}$.

\footnotetext{
${ }^{8}$ A pesquisa, feita entre julho e agosto de 2006, realizou entrevistas em áreas urbanas das 5 regiões do país. Fonte (acesso em 15/11/2006): www.agencia.fapesp.br/boletim_dentro.php?id=6343.

${ }^{9}$ É uma crise latejante pois ela está sempre presente, com intensidade maior ou menor. Como afirma Milton Santos: "No mundo atual, o despotismo do dinheiro está ligado a uma lógica auto-referida e autoexplicativa, uma espécie de cachorro dando voltas e mordendo o rabo, razão pela qual busca remédio aos seus próprios tropeços mediante novas construções matemáticas" [...] "Por isso, quando tais lógicas são impostas a todas as situações, agudizam heterogeneidades e assimetrias e provocam fraturas e fragmentações" (SANTOS, 2002b, p. 47).
} 
TOZI, F. O território como recurso: a privatização das telecomunicações ...

O território, por não ser palco, mas condição ativa da nação, impõe, nas fragmentações, ou crises, a sua condição desigual, revelando o espaço de todos em oposição ao espaço das redes, este que é privilegiado pelas empresas e pelos governos. É por esta resistência ao pensamento único e à economia única, que trata-se de uma privatização do território, e não de um território definitivamente privatizado, o que induziria a pensar num fato acabado. A privatização é um movimento, parte de um processo que não se completa, e que pode, dependendo dos projetos e dos agentes sociais, avançar tanto em direção ao aprofundamento do capitalismo quanto ser abolida em direção a formas mais democráticas de uso do território. A privatização das telecomunicações, e de outros elementos fundamentais à vida neste momento da história, é reversível, como nos mostram os eventos ocorridos em diversos países da América Latina, nos quais concessões públicas foram revogadas, conforme discutimos mais detalhadamente em Tozi (2005).

É ilusão esperar que da racionalidade sistematicizada resulte uma compreensão das carências do território brasileiro. Tudo que dela se pode esperar é a contínua progressão da racionalização das condições da vida, pois as corporações não pensam o território como abrigo, apenas como recurso. Quanto ao Governo, apresentase nacional e internacionalmente comprometido com esta mesma racionalidade, e está claro que a ausência de uma política de telecomunicações é uma política, ou seja, que a passividade é ativa. E se por um lado a estrutura existente (a inércia do mundo) impede ações, outras são intencionais. Os problemas regulatórios, a crise que se passa a cada novo movimento das empresas, que não encontram limites nas normas nacionais, é nada mais que um aspecto situacional do abandono da consciência de um país.

Assim, é fundamental que uma política genuína pense o território, uma totalidade, e não o setor, porque a idéia de setor não favorece aos cidadãos, mas às empresas, eliminando a responsabilidade que elas têm sobre a totalidade social, sobre as desigualdades socioterritoriais. Há que se pensar, a partir das 
TOZI, F. O território como recurso: a privatização das telecomunicações ...

desigualdades nacionais, uma integração democrática do país, que permita uma fluidez produtiva, e não competitiva, tendo o território como abrigo de um povo, seu dono verdadeiro, e não como recurso a empresas que já explicitaram, em suas ações, a mesquinhez dos seus projetos.

\section{Referências bibliográficas}

AZEVEDO, S.J.S. de. Contribuições demográficas para a formulação de ações políticas - $\quad$ o exemplo das telecomunicações em Campinas (SP). Dissertação de Mestrado. Campinas: Nepo/Unicamp, 2005.

BIONDI, A. O Brasil privatizado - edição especial. São Paulo: Editora Fundação Perseu Abramo, 2001 [1999/2000].

BORON, A. A crise do neoliberalismo e os perigos do possibilismo. Disponível em: http://resistir.info. 2004.

CANO, W. Soberania e política econômica na América Latina. São Paulo: Editora UNESP, 2000.

CATAIA, M. A alienação dos territórios frente aos processos da globalização econômica. Mimeo, 2003.

CHAUÍ, M. Mito fundador e sociedade autoritária. São Paulo: Editora Fundação Perseu Abramo, 2000.

DALMAZO, R. A. "Os atores, os interesses e as mediações cruciais na privatização da Telebrás”. In: Ensaios FEE. Porto Alegre: v. 21, n.1, 2000.

DANTAS, M. A lógica do capital informação. A fragmentação dos monopólios e a monopolização dos fragmentos num mundo de comunicações globais. Rio de Janeiro: Contraponto, 2002.

IANNI, O. "A formação do capitalismo nacional". Trecho do capítulo inédito ' 7 teses sobre o Brasil Moderno'. In: Jornal da Unicamp. n. 248. Campinas: Unicamp, 2004. 
TOZI, F. O território como recurso: a privatização das telecomunicações ...

IOZZI, F.L. Políticas territoriais das empresas de telecomunicações no Brasil: universalização do serviço de telefonia fixa. Dissertação de Mestrado. Campinas: IG/Unicamp, 2005.

PINHEIRO, A.C.; GIAMBIAGI, F. "Os antecedentes macroeconômicos e a estrutura institucional da privatização no Brasil". In: PINHEIRO, A.C.; FUKASACU, K. (editores). A privatização no Brasil - o caso dos serviços de utilidade pública. Rio de Janeiro: BNDES, 2000.

PINHEIRO DA FONSECA, J.C. "O Terremoto chegou”. In: A Privatização do século. Revista Brasileira de Telecomunicações (Telebrasil). Rio de Janeiro: Julho/ agosto, 1998.

RIBEIRO, A.C.T. "Sistema, Período e Ação: Desafios de uma Herança". In: Ciência Geográfica. n. VII; Vol. II. Bauru: MaioAgosto, 2001.

SANTOS, B. de S. Pela mão de Alice. O social e o político na pós-modernidade. São Paulo: Cortez, 1997.

SANTOS, M. Por uma outra globalização. Do pensamento único à consciência universal. São Paulo: Record, 2000.

SANTOS, M. "Da Política dos Estados à Política das Empresas". In: Cadernos da Escola do Legislativo. n.6. julho/dezembro. Minas Gerais, 1997.

SANTOS, M. A Natureza do Espaço: Técnica e Tempo, Razão e Emoção. São Paulo: Hucitec, 1996.

SANTOS, M. Técnica, Espaço, Tempo. Globalização e meio técnico-científico informacional. São Paulo: Hucitec, 1994a.

SANTOS, M. "O retorno do Território". In: SANTOS, M; SOUZA, M.A. de; SILVEIRA, M.L. Território - Globalização e Fragmentação. São Paulo: Hucitec, 1994b.

SANTOS, M. O espaço do cidadão. São Paulo: Nobel, 1987. 
TOZI, F. O território como recurso: a privatização das telecomunicações ...

SANTOS, M.; SILVEIRA, M.L. O Brasil - Território e Sociedade no início do século XXI. São Paulo: Record, 2001.

SILVEIRA, M. L. Argentina: Território e Globalização. São Paulo: Brasiliense, 2003.

SOUZA, M.A. de. "A Metrópole global? Refletindo sobre São Paulo". In: SOUZA, M.A. de (et al). Metrópole e globalização conhecendo a cidade de São Paulo. São Paulo: CEDESP, 1999.

TOZI, F. As privatizações e a viabilização do território como recurso. Dissertação de Mestrado. Campinas: IG/Unicamp, 2005.

Recebido em junho de 2008 Aceito em agosto de 2009 